\title{
Bodas de plata de la reacción en cadena de la polimerasa (PCR)
}

\author{
Gladys Pinilla B1, Karen Cubillos², Mónica Rodríguez ${ }^{1,3}$ \\ 1. Universidad Colegio Mayor de Cundinamarca, Bogotá - Colombia. \\ 2. Instituto de Biotecnología Universidad Nacional, Bogotá - Colombia. \\ 3. Universidad Nacional Posgrado de Microbiología \\ Correspondencia: gpinillab@gmail.com
}

Recibido 27-04-08 / Aceptado 19-05-08

\begin{abstract}
Resumen
Invenciones verdaderamente revolucionarias han promovido el cambio de pensamiento y la manera de trabajar en el ámbito del laboratorio. Una de estas invenciones es la reacción en cadena de la polimerasa, la cual ha aportado de manera significativa al conocimiento científico. Las diferentes metodologías que aplican la reacción en cadena de la polimerasa han permitido a los investigadores manipular la información genética de los organismos, facilitando procedimientos como la clonación y la secuenciación, entre otros, lo cual agilizó significativamente los resultados del Proyecto Genoma Humano. Existe diversidad de variantes de la reacción en cadena de la polimerasa convencional. Este escrito tiene por objetivo presentar una revisión sobre el tema, especialmente sobre la reacción en cadena de la polimerasa en tiempo real, debido a las ventajas que ofrece.

Palabras clave: agentes intercalantes, cuantificación absoluta, cuantificación relativa, curvas de calibración, gen normalizador, sondas fluorogénicas.
\end{abstract}

\section{Abstract \\ Silver anniversary of the Polymerase Chain Reaction (PCR)}

Truly revolutionary inventions have promoted the change of thought and the way to work in the laboratory. One of these inventions is the polymerase chain reaction (PCR), which has contributed significantly to the scientific knowledge. The different methodologies that use the polymerase chain reaction have allowed investigators to manipulate the genetic information of organisms, facilitating procedures like cloning and sequencing, among others, which sped the Human Genome Project results significantly. There are several variants of the conventional polymerase chain reaction. This work tries to present a revision on the subject, especially on the Real-time polymerase chain reaction, due to the advantages that it offers.

Key words: absolute quantification, calibration charts, fluorescent probe, normalizing gene, intercalate agents, relative quantification, 


\section{Introducción}

La reacción en cadena de la polimerasa (PCR) fue creada por Kary B. Mullis en 1983. En sus 25 años de evolución ha contribuido de manera significativa en los procesos investigativos básicos y de diagnóstico en gran cantidad de patologías. Esta estrategia metodológica le permitió a Mullis en 1993 ganar el premio Nobel de química, considerado como una revolución para el desarrollo de la biología molecular (1).

En 1989, Science seleccionó la PCR como el principal desarrollo científico y la Taq polimerasa como la molécula del año. El principio de la PCR consiste en determinar la secuencia de interés y seleccionar pequeños segmentos de nucleótidos llamados iniciadores o cebadores, complementarios con la secuencia de nucleótidos de los extremos opuestos de las cadenas que flanquean a dicha secuencia, a partir de los cuales mediante la acción de la Taq polimerasa, se inicia la elongación o síntesis de nuevas cadenas en el extremo 3' de cada iniciador, para obtener múltiples copias de dicho segmento $(2,3)$.

Las aplicaciones de la PCR son múltiples, entre ellas la amplificación de fragmentos de genes, modificación de fragmentos de $\mathrm{ADN}$, detección sensible de microorganismos y su genotipificación, análisis de muestras arqueológicas y estudios antropológicos, la detección de mutaciones importantes en enfermedades hereditarias, transformación maligna o tipaje de tejidos, el análisis de marcadores genéticos para aplicaciones forenses, pruebas de paternidad y mapeo de rasgos hereditarios, estudio de expresión de genes y farmacogenómica, entre otras (4-6).

\section{Variantes de la PCR convencional}

Existe diversidad de variantes de la PCR convencional, algunas de las cuales se presentan en esta revisión, sin embargo este artículo se enfoca en la PCR en tiempo real (PCRtr).

PCR inversa: se emplea para clonar regiones desconocidas de un $\mathrm{ADN}$, situadas en posición vecinal a secuencias diana conocidas. Es decir, en lugar de amplificar la región interna, flanqueada por los dos iniciadores (PCR convencional), se amplifica la región externa que flanquea los iniciadores. Para ello es necesario cortar el ADN a ambos lados de la región diana con una enzima de restricción, de tal forma que los extremos cohesivos resultantes puedan hibridar entre si, formando una molécula circular. Esta es cerrada por una ligasa y se realiza la PCR con iniciadores que hibridan los extremos 5' de la secuencia conocida, por lo que la elongación se extenderá alrededor del círculo generando copias de ADN delimitado (7).

PCR anidada (Nested-PCR): aumenta la especificidad al realizarse una segunda reacción de PCR, con dos iniciadores nuevos que hibridan dentro del fragmento diana amplificado en la primera reacción, permitiendo la obtención de productos de PCR más cortos y específicos (8).

PCR con adaptadores: permite amplificar una región de $\mathrm{ADN}$ de secuencia desconocida, ligando a fragmentos de restricción, secuencias adaptadoras, es decir oligonucleótidos sintéticos con extremos cohesivos compatibles con los generados en la muestra. Los iniciadores son específicos para las secuencias 3' de los adaptadores, permitiendo la amplificación del conjunto de adaptadores y secuencia diana (8).

PCR asimétrica: se trata de generar copias de hebra sencilla de un $\mathrm{ADN}$. Es la variante más simple, en la que se añaden diferentes concentraciones de ambos iniciadores, de modo que tras los primeros ciclos de PCR uno de ellos se agota y deja disponible suficientes copias del ADN diana. Solo una de sus hebras sigue amplificando gracias al iniciador más abundante (7).

PCR larga (L-PCR): su objetivo es superar los límites de la PCR convencional para amplificar con fidelidad regiones diana de gran tamaño (entre 5 y $40 \mathrm{~kb}$ ), las cuales son muy convenientes para amplificar genomas virales, intrones, $\mathrm{ADN}$ mitocondrial y grupos de genes (8).

PCR múltiplex: las reacciones de PCR ocurren simultáneamente y en un mismo tubo, amplificando diferentes secuencias diana, para lo cual se usan varias parejas de iniciadores, permitiendo la detección e identificación simultánea de distintos genes de interés (9).

RT-PCR (PCR con transcriptasa inversa): a partir de ARN diana y mediante la transcripción reversa del ARN a ADNc, puede ser utilizado para la amplificación, detección de la expresión de genes específicos o almacenaje de $\mathrm{ADNc}_{\mathrm{C}}(7)$. 


\section{PCR en tiempo real}

\section{Generalidades}

La cuantificación de la expresión o cantidad de ARNADN presente en una muestra se realizó inicialmente mediante PCR competitiva. Pero fue desde finales de 1990 cuando la cuantificación de la expresión logra importancia en la práctica clínica; sin embargo, la PCRtr también permite la identificación de nuevos genes y polimorfismos, el conocimiento de anomalías cromosómicas estructurales y epigenéticas (10).

La primera reacción de PCR en tiempo real se llevó a cabo utilizando el marcador fluorescente bromuro de etidio, el cual aumenta su fluorescencia al unirse al ADN y la reacción de PCR se evidenció con una videocámara. El primer equipamiento para realizar PCR en tiempo real fue comercializado en 1996 por Applied Biosystems. Posteriormente se fueron incorporando distintas empresas como BioGene, Bioneer, Bio-Rad, Cepheid, Corbett Research, Idaho Technology, MJ Research, Roche, Applied Science, y Stratagene. En los equipos actuales, la detección del sistema incorpora módulos ópticos que son capaces de detectar secuencias seleccionadas marcadas con fluorocromos $(6,10,11,13)$.

En la PCRtr, los procesos de amplificación y detección se producen de manera simultánea en el mismo vial cerrado, sin necesidad de ninguna acción posterior. Además mediante la detección por fluorescencia se puede medir durante la amplificación la cantidad de $\mathrm{ADN}$ o

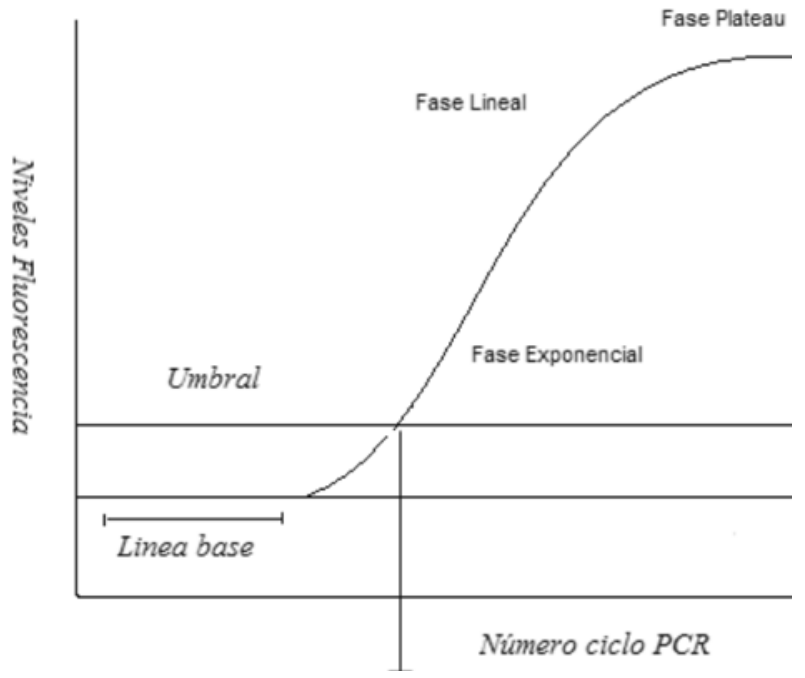

Figura 1. Cinética de la PCRtr.
ARN sintetizado en cada momento, ya que la emisión de fluorescencia producida en la reacción es proporcional a la cantidad de ADN o ARN formado, lo que permite conocer y registrar en todo momento la cinética de la reacción de amplificación. La cuantificación de la muestra por PCRtr incrementa la fiabilidad del análisis de la expresión del gen (12).

\section{Cinética de la PCRtr}

En la Figura 1 se observa la fase exponencial, fase lineal y fase Plateau. Ct, corresponde al inverso del log del número de copias. La línea de base es el nivel basal o background de fluorescencia durante los primeros ciclos de PCR. El umbral es el nivel de fluorescencia fijo por encima de la línea base. En la fase exponencial temprana la fluorescencia supera el umbral. En la fase logarítmica lineal se duplica exactamente el producto en cada ciclo (óptima amplificación). Y en la fase de plateau, los reactivos se consumen, la reacción se detiene (reacción de punto final).

La cinética de amplificación de PCRtr evidencia la acumulación de la emisión de fluorescencia en cada ciclo de reacción, y esta puede ser clasificada en cuatro fases. En esta cinética es importante resaltar el Umbral o Threshold (nivel de fluorescencia fijo por encima de la línea base) y el Ct ó Cp: (ciclo del umbral o punto de cruce o corte), ciclo en el cual la fluorescencia supera el umbral y es detectada. El Ct es inversamente proporcional a la concentración inicial de ADN o ARN diana presente en la misma; los datos que se obtienen permiten calcular la eficiencia de la amplificación (14-17).

\section{Eficiencia de la PCRtr}

Es la proporción a la que un amplicon de PCR se genera, normalmente expresado con un valor en porcentaje. Sí un amplicon dobla la cantidad durante la fase logarítmica de su amplificación por PCR, el ensayo tiene $100 \%$ eficiencia (18). La curva estándar de la PCRtr es representada gráficamente como el semi-log del valor de CT versus el log del acido nucléico inicial; una pendiente de la curva estándar de -3.32 indica una reacción de PCR con $100 \%$ eficiencia, mientras que pendientes más negativas que -3.32 (ej. -3.9) indica reacciones que tienen menos del 100\% de eficiencia, Figura 2. Pendientes más 


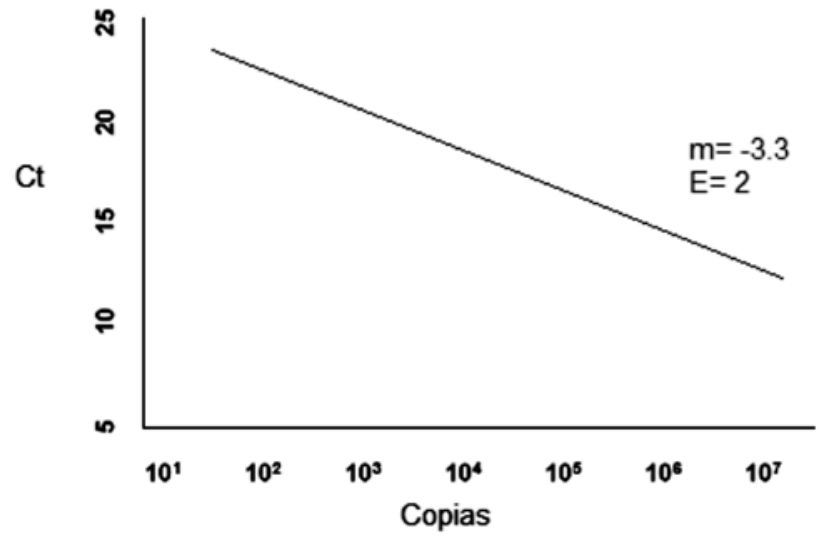

Figura 2. Gráfica eficiencia.

$\mathrm{E}=10-1 / \mathrm{m}$

$y=m x+b$

Pendiente aceptable entre -3.2 y -3.8

Eficiencias entre: 83 y 105\% =2 (Doble de copias)

positivas que -3.32 puede indicar problemas de calidad de la muestra o problemas de pipeteo.

La eficiencia de la PCRtr puede ser estimada mediante curvas de calibración realizadas con diluciones seriadas de un estándar que puede ser ADN o un plásmido (19). Los parámetros que afectan la eficiencia de PCR son: especificidad de primers y sondas, concentraciones altas de dNTPs (20), agentes inhibidores como hemoglobina, heparina, IgG, altas concentraciones de proteína $(21,22)$.

\section{Agentes intercalantes}

Los sistemas de detección por fluorescencia empleados en la PCRtr pueden ser agentes intercalantes y sondas específicas marcadas con fluorocromos (13). Los agentes intercalantes son fluorocromos que aumentan notablemente la emisión de fluorescencia cuando se unen al ADN de doble hélice. El más empleado es el SYBR Green I. El incremento del ADN en cada ciclo se refleja en un aumento proporcional de la fluorescencia emitida. Este sistema de detección tiene la ventaja de que la optimización de las condiciones de la reacción es fácil y más económica que las sondas específicas. Para mejorar la especificidad se deben emplear condiciones de reacciones óptimas y una selección cuidadosa de los primers para disminuir el riesgo de la formación de dímeros; además, es recomendable iniciar la reacción de síntesis de $\mathrm{ADN}$ a temperaturas elevadas (hot-start PCR).

La mayoría de los equipos para PCR en tiempo real tienen la posibilidad de determinar la temperatura de fusión de los fragmentos amplificados $(\mathrm{Tm}=$ temperatura a la que el 50\% de la molécula de ADN está desnaturalizado). Cada fragmento amplificado tiene una Tm característica, que depende sobre todo de su longitud y de la composición de sus bases; esta aplicación permite comprobar, la especificidad de los fragmentos detectados en la PCR $(16,23)$.

\section{Ventajas SYBR Green}

- Diez veces más sensible que el bromuro de etidio.

- Más económico que el uso de sondas.

- Una sóla química para todos los experimentos.

- $\quad$ No requiere diseño de sondas.

\section{Desventajas SYBR Green}

- Requiere ajustar de manera más exhaustiva las condiciones.

- Difícil genotipificación de SNPs.

- $\quad$ No permite hacer PCR multiplex.

- Baja especificidad, debido a que se unen de manera indistinta a productos generados.

\section{Análisis de curvas de disociación}

Al utilizar como agente químico para la PCRtr el SYBR Green, se debe realizar la curva de disociación, para comprobar la especificidad de los fragmentos detectados
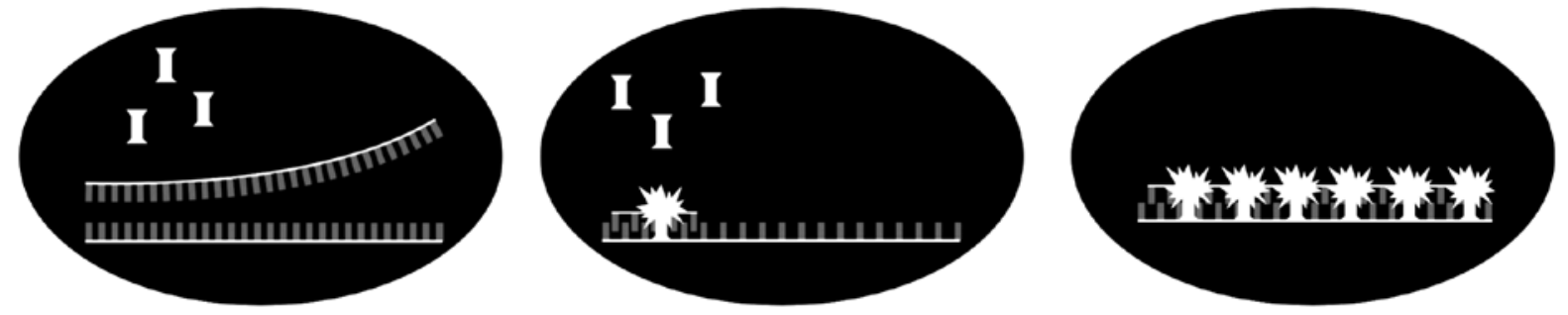

Figura 3. SYBR Green. Acción intercalante a lo largo de la cadena de DNA emitiendo fluorescencia 
PRIMER MARCADO

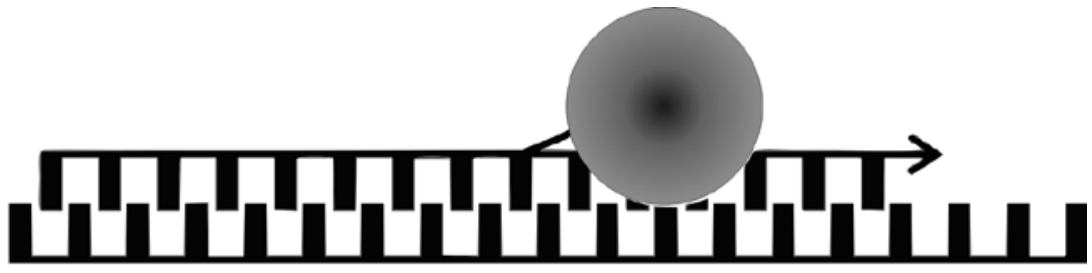

EXTENSIÓN, EMISIÓN FLUORESCENCIA

Figura 4. Efecto LUX (light upon extensión). El iniciador marcado con el fluoroforo emite fluorescencia en el momento que se hibrida con su blanco.

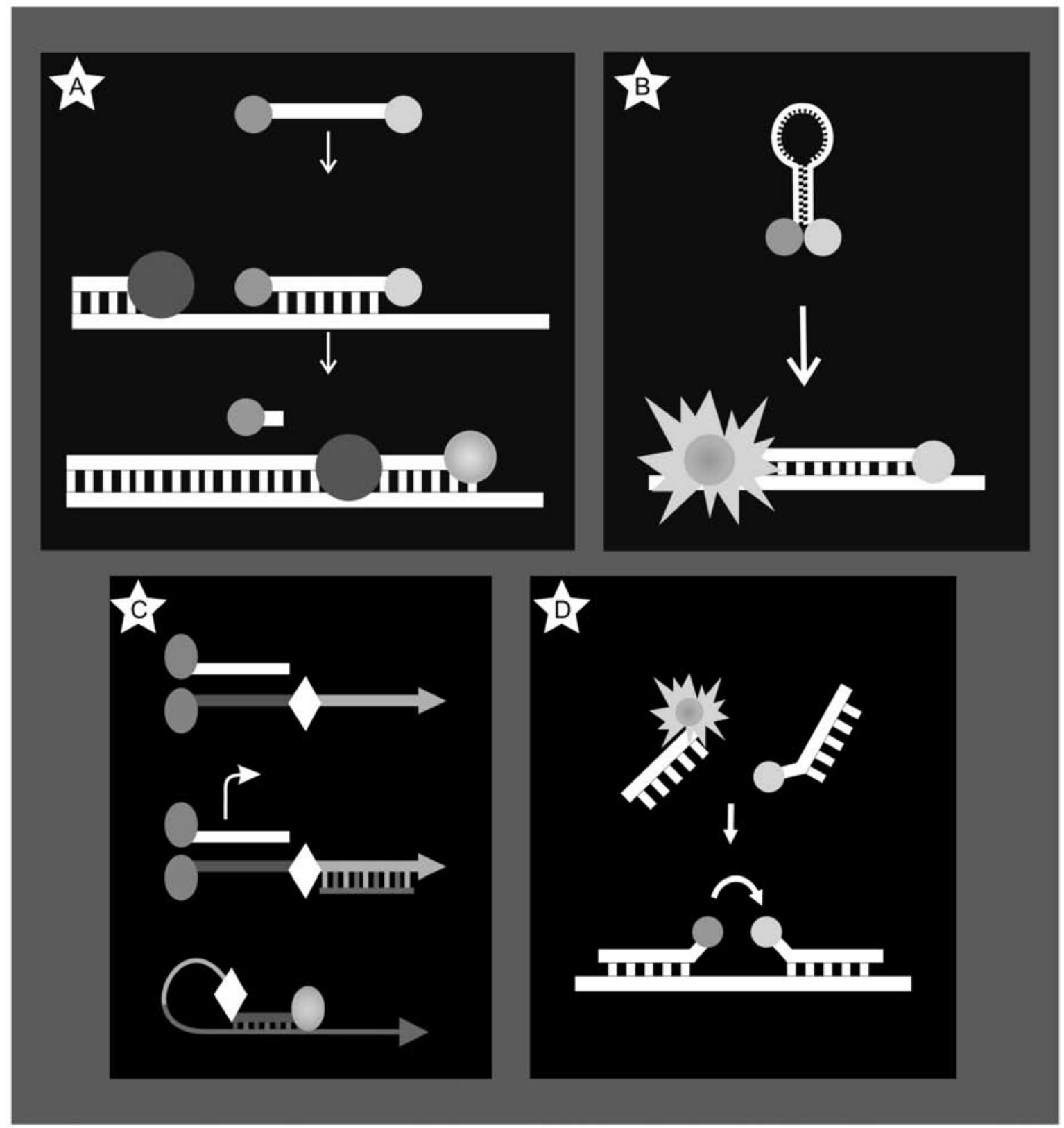

Figura 5. Sondas Hibridación: A. Sonda Taqman, B. Molecular Beacons, C: Iniciador escorpión y D: De hibridación. Sondas de PCR tiempo real que funcionan bajo el principio FRET, transferencia de energía fluorescente mediante resonancia 
en la PCR. La curva de disociación se basa en un gradiente de temperaturas crecientes después de la PCRtr, para monitorizar la cinética de disociación de los fragmentos amplificados y comprobar su especificidad. Es decir, se detecta la amplificación del blanco ADN o ARN (primera derivada) y dímeros de primers (segunda derivada).

\section{Iniciadores marcados con fluoroforos}

"Los primers LUX fluorogenic" son un nuevo producto que permiten la detección de la secuencia blanco por emisión de fluorescencia. LUX (light upon extension) es un iniciador específico a la secuencia de interés que se encuentra marcado con un fluoroforo, cuando el iniciador se hibrida con la cadena blanco, el fluoroforo es excitado, resultando en incremento significativo de señal de fluorescencia, Figura 4. Este producto tiene como ventaja que es menos costoso que las sondas y más sensible que el SYBR Green $(17,24)$.

\section{Sondas de hibridación}

Son sondas marcadas con dos tipos de fluorocromos, un donador y un aceptor. El proceso se basa en la transferencia de energía fluorescente mediante resonancia (FRET) entre las dos moléculas. Este principio consiste en que una molécula de alta energía cercana a una molécula de baja energía (quencher), promueve una transferencia energética y no habrá emisión de fluorescencia. Una vez se separan dichas moléculas se emite la fluorescencia que es captada por el lector del equipo (25).

Entre las sondas se encuentran:

Sondas TaqMan: sonda corta que necesita la ruptura de la polimerasa para separar las dos moléculas fluorecentes y liberar fluorescencia, Figura 5A (26).

Molecular Beacons: sonda cerrada que hibrida con su blanco durante la PCR liberando fluorescencia, Figura 5B (4).

Iniciador escorpión: incluye un iniciador de PCR, que al unirse con una región especifica del ADN blanco, el oligonucleótido unido al quencher se libera, plegándose la sonda marcada con el fluorocromo sobre el acido nucléico blanco liberando la fluorescencia, Figura 5C.

Sondas de hibridación: conformada por dos sondas. Si está hibridada no emite fluorescencia a temperatura de $55^{\circ} \mathrm{C}$, se libera la fluorescencia en fase de desnaturalización a $95^{\circ} \mathrm{C}$, Figura $5 \mathrm{D}(6,17)$.

\section{Controles para PCR}

Control Interno: se define como una secuencia de $\mathrm{ADN}$ o $\mathrm{ADN}$ c que es co-amplificado con el ADN blanco y se usa principalmente para aumentar la confiabilidad de los ensayos, ya que permite la detección de falsos negativos. Es decir determina un ensayo fallido o inhibición de la reacción. El control interno más usado para la PCRtr es un plásmido que contiene secuencias de organismos distantes filogenéticamente. Estos plásmidos pueden ser adicionados a la mezcla de PCR o directamente a la muestra clínica (de esta forma se verificaría si la extracción de ADN a partir de la muestra se llevó a cabo correctamente). La longitud del templado del control interno debe ser mayor a la longitud del templado de ADN blanco para asegurar que la competencia de la reacción tienda más hacia el último (27).

Control positivo ó externo: no permite verificar la reacción individualmente ya que la reacción se da en un tubo diferente; no revela la ineficiencia en la extracción de ADN o ARN.

Control negativo: se puede utilizar otro organismo no relacionado con el organismo en estudio, o también se puede utilizar agua o buffer en lugar de ADN templete. Este control puede ser utilizado a la vez como control ambiental $(28,29)$.

\section{Tipos de detección}

1. Cualitativa: presencia de secuencia blanco en la muestra.

2. Cuantitativa:

Absoluta: cantidad moléculas en valor absoluto.

- Curva estándar.

- Relativa: relación entre la expresión del gen blanco y un gen de referencia.

- Se requiere hallar el $\Delta \Delta \mathrm{CT}(\Delta \mathrm{CT}$ del gen blanco y $\triangle \mathrm{CT}$ del gen de referencia)(30).

- Método PFaffl.

\section{Cuantificación absoluta}

En la cuantificación absoluta se realiza la comparación con amplificados de los cuales se conoce el número absoluto de moléculas iníciales a cuantificar (estándares), se amplifican en una misma reacción con la muestras de interés, pero en tubos diferentes. La curva estándar utiliza diluciones seriadas 


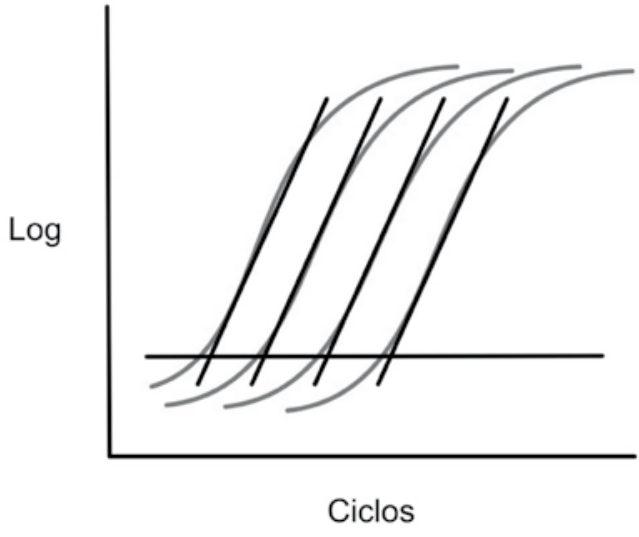

Figura 6. Curva estándar para cuantificación absoluta.

(mínimo 5) de estándares de concentraciones conocidas; el número de moléculas es calculado como una extrapolación a partir de una curva generada por los estándares. Este método asume que todos los estándares y las muestras tienen aproximadamente igual eficiencia de amplificación. Se obtiene el valor absoluto como número de copias, células, $\mu \mathrm{g} / \mu \mathrm{l}$, etc., Figura $6(17,30,31)$.

\section{Cuantificación relativa}

Permite cuantificar las diferencias en la expresión del gen blanco relativo a la expresión del gen normalizador (30). La cuantificación relativa es útil y sencilla para analizar la expresión entre genes $(31,32)$.

Expresión Relativa $=\frac{\left(\mathrm{E}_{\text {blanco }}\right)^{\Delta C \mathrm{~T}_{\text {blanco (control-muestra) }}}}{\left(\mathrm{E}_{\text {ref }}\right)^{\Delta C \mathrm{~T}_{\text {ret (control-muestra) }}}}=\frac{\left(\mathrm{E}_{\text {blanco }}\right)^{-\Delta C \mathrm{~T}_{\text {blanco (muestra - control) }}}}{\left(\mathrm{E}_{\text {ref }}\right)^{\Delta C \mathrm{~T}_{\text {ref (muestra - control) }}}}$

\section{Método de Ct comparativo (Método $\Delta \Delta C T$ )}

El método de CT comparativo, también llamado el método de $\Delta \triangle \mathrm{CT}$, es similar al método de la curva estándar relativa, excepto que este usa las fórmulas aritméticas para lograr un resultado para la cuantificación relativa. Es posible eliminar el uso de curvas estándar y usar el método de $\Delta \triangle \mathrm{CT}$, pero las eficacias de PCR entre el blanco (s) y control (s) (endógeno) deben ser relativamente equivalentes (16). La ventaja de este método es que no exige curvas estándar para cada pozo de reacción, permitiendo el ahorro de reactivos y es útil cuando hay un número alto de blancos y/o de muestras (33).

\section{Normalizadores}

Los normalizadores son un grupo de genes que se expresan en todas las células del organismo y codifican para proteínas que son esenciales para el funcionamiento general de las células; pueden ser expresados en diferentes condiciones experimentales incluyendo diferentes tejidos o tipo de células. Su expresión no debe ser muy diferente del gen blanco y la estabilidad y tamaño debe ser parecido a los genes de interés. Los datos de la expresión de genes normalizadores son utilizados para corregir la variación muestra-muestra y compensar el error experimental $(28,29)$.

Recientes estudios muestran que la expresión de muchos genes, que son usados como normalizadores en experimentos en PCRrt, pueden ser influenciados por la actividad metabólica, por la fase de crecimiento y por las condiciones experimentales. Por lo cual la normalización con un único gen "Housekeeping" puede falsear los resultados. Recientes estudios proponen el uso de dos o más genes normalizadores (16).

Genes que se han estudiado durante crecimiento in vitro y bajo diferentes condiciones para determinar cuales pueden ser utilizados como normalizadores para la expresión de genes bacterianos son:

Gen 16S rRNA: (1500pb) parte esencial del complejo ribosomal. La concentración celular de ribosomas es proporcional a la síntesis de proteína total y de la actividad metabólica celular. Por lo cual es un buen marcador del contenido ribosomal, cuyos transcriptos tienen una estabilidad excepcional, ya que el $90 \%$ de todos ellos, durante la fase logarítmica, tienen una vida media de 5 minutos y estabilidad hasta por 3 horas $(34,35,36)$.

Gen gmk: (2937 pb), codifica una enzima (guanilato kinasa) esencial para la síntesis de guanosina. Es un componente del metabolismo celular bien conocido, que puede variar considerablemente bajo diferentes condiciones $(35,37,38)$.

Gen tpi: $(3373 \mathrm{pb})$, representa un gen Houeskeeping vital, su producto (triosefosfato isomerasa) es esencial durante la glicolisis. Las secuencias que codifica este gen tanto en eucariotas como en procariotas son altamente conservadas entre especies filogenéticamente distintas $(39,40)$.

Gen $\boldsymbol{d} f \boldsymbol{f h r}:(3309 \mathrm{pb})$ su producto, la dihidrofolato reductasa esencial para la síntesis del ácido fólico; es clave en el camino del tetrahidrofolato y esencial en la biosíntesis de las purinas, timidilato y varios aminoácidos (35). 
Gen hsp-60: está involucrado en el plegamiento y ensamblaje de proteínas y en la reactivación de proteínas denaturadas (35).

Gen $f a b D$ : codifica para una proteína presente en todas las bacterias, la malonil CoA-ACP transacetilasa (MCAT). Esta enzima, esencial para la biosíntesis de ácidos grasos (sustrato para la elongación durante la síntesis de ácidos grasos) y por tanto importante en la síntesis de los ácidos micólicos (35).

Entre otros normalizadores están el gen glyA, gyrA, pyk, recF, rho, rpoD, rrsC (41-43).

Como normalizadores para la expresión de genes humanos se han usado:

rRNA ribosomal 28S: es uno de los más usados, que ha mostrado la mayor estabilidad en una gran variedad de tejidos. No es tan conservado en diferentes especies; puede permanecer intacto en caso de degradación, constituye más del 50\% del RNA total y su expresión se afecta por procesos celulares y drogas (44).

Actina: uno de los mayores componentes de los microfilamentos del citoplasma en eucariotas, tiene diferentes papeles en funciones celulares, principalmente en estructura y morfología celular. Su expresión se ha visto alterada en tejidos en diferentes estados de desarrollo, diferentes cultivos de tejidos, bajo la infección de patógenos. En general no se recomienda su uso en condiciones que afecten la morfología celular (44).

GAPDH: (Gliceraldehido 3-fosfato deshidrogenasa) es una enzima multifuncional involucrada en metabolismo celular. Al ser un gen de bajo número de copias tiene una baja frecuencia de isoformas o pseudogenes lo que disminuye la posibilidad de reacción cruzada. Su expresión se ha visto alterada en hipoxia, líneas celulares cancerígenas, en ontogenia y pancreatitis aguda (25).

Ciclofilina: tiene función en la catálisis del doblamiento de proteínas por rotación del enlace peptídico en los enlaces de serinas, actúa como chaperona en el tráfico de proteínas así como en la degradación nucleolítica del genoma. Su expresión se ha visto alterada en diferentes etapas de desarrollo y bajo ciertos tipos de estrés como choque térmico, infección viral, y en exposición ante el acido salicílico (45).

EF-1 $\alpha$ : (Elongation Factor 1a) es una proteína ubiquita que une los tARN a los ribosomas durante la síntesis de proteínas. Al ser parte del sistema de traducción, su expresión se puede ver afectada en tejidos de rápido crecimiento y desarrollo como meristemos vegetales. Se ve afectada también en situaciones que alteran el crecimiento y desarrollo celular como muerte y envejecimiento celular (45-47).

\section{Algunas aplicaciones}

\section{Evaluación de la expresión génica}

Para la evaluación de la expresión génica mediante los métodos clásicos se requiere de una gran cantidad de ARN mensajero que es difícil de obtener cuando el número de muestras es limitado o cuando el material biológico es una población de diferentes tipos (25). Esta técnica ha sido usada para la cuantificación de ARN de diversas células como es el caso de la expresión génica de los ovocitos. Los estudios sobre la oogenesis son escasos, dado que la diferenciación se lleva a cabo en estadios fetales, por lo que son inaccesibles a la manipulación experimental, y la cantidad de material biológico disponible para su análisis es escaso, Por lo tanto esta técnica abre las posibilidades para ser utilizada en el análisis molecular de células obtenidas de cultivos biológicos o mediante microdisección con láser (48).

\section{Diagnóstico microbiológico en alimentos}

El diagnóstico automatizado de patógenos en alimentos, continua siendo una necesidad para la industria y la salud pública, debido a esto la PCR se convirtió en una herramienta poderosa para el diagnostico microbiológico, pero debe cumplir óptimamente muchos criterios analíticos, alta probabilidad de detección, baja contaminación y protocolos cómodos para la aplicación y la interpretación. La segunda generación de la PCR, es decir en tiempo real, tiene la precisión y el potencial para la detección en un solo paso; además la cuantificación del patógeno no se basa en un punto final sino en un incremento exponencial de la cantidad de ADN inicial (49).

La PCRtr esta siendo implementada para detectar microorganismos patógenos en alimentos, en muestras ambientales y en muestras clínicas. El diagnóstico molecular de salmonelosis no tifoidea, cada vez se pone mas en auge, debido a la alta incidencia de intoxicación alimentaría asociada con la contaminación de alimentos 
de origen animal como huevos y la carne de pollo $(49,50)$. La PCRtr es una herramienta fiable y rápida para el monitoreo de las muestras alimenticias a lo largo de la cadena de producción ya que en tan solo 24 horas se detectan células en suspensión de $103 \mathrm{UFC} / \mathrm{ml}$ con una probabilidad del $70 \%$ o $104 \mathrm{UFC} / \mathrm{ml}$ con una probabilidad del $100 \%(50,51,52)$.

La bacteria Clostridium botulinum, es la responsable del botulismo, enfermedad neuroparalitica. Siete tipos de toxinas antigénicas han sido identificadas (A-G) BoNT (neurotoxina botulínica) tipo A, B E y raramente $\mathrm{F}$ son las responsables de botulismo humano (53). Esta bacteria puede contaminar alimentos mal enlatados o almacenados en recipientes abiertos o inapropiados. Los métodos microbiológicos estándar toman sólo en consideración la detección de $C$. botulinum; el bioensayo en ratones es el método universal, altamente sensible, pero costoso y con problemas éticos ya que requiere gran cantidad de animales. La detección de genes de BoNT por PCRtr es más sensible y una alternativa mas rápida que los bioensayos $(53,54)$.

\section{Diagnostico microbiológico clínico}

El descubrimiento temprano y el tratamiento adecuado para la infección bacteriana tienen un gran impacto ya que en la mayoría de las infecciones se tratan empíricamente con antibióticos de amplio espectro debido al tiempo que se requiere, de 24 a $48 \mathrm{~h}$ para el procesamiento microbiológico de rutina (55).

Actualmente en pacientes en cuidado crítico, que requieren la detección temprana de $\mathrm{ADN}$ bacteriano en el torrente circulatorio, es posible analizar las muestras clínicas como sangre (56), plasma (57), fluido cerebroespinal (58, 59) y otros especímenes mediante PCRtr $(59,60)$. En contraste con estos nuevos acercamientos de diagnóstico, los cultivos de sangre requieren más tiempo y a menudo brindan resultados falsos negativos, debido a baja sensibilidad (61).

La PCRtr, se ha usado para la identificación de mutaciones puntuales asociadas con resistencias a fármacos antimicrobianos (62). En sólo una hora se puede determinar la presencia en heces de Enterococos resistentes a vancomicina (18), facilitando el control de la transmisión de este patógeno. También se ha empleado en la detección de mutaciones asociadas con resistencias a meticilina $(31,63)$ en $S$. aureus, a rifampicina y a isoniacida en Mycobacterium tuberculosis (18), y de mutaciones asociadas con resistencia a agentes antivíricos, como la lamivudina en VHB (41).

Existe gran variedad de enfermedades ocasionadas por microorganismos que requieren diagnostico temprano. Dentro de estas, la neumonía adquirida en la comunidad o nosocomial causada por la Legionella pneumophila, que se caracteriza por su crecimiento lento, por requerir medios de cultivo selectivos y periodos prolongados de incubación. Para su diagnostico se usa generalmente métodos serológicos, sin embargo la detección de IgG e IgM no permite el diagnostico temprano. Se ha probado la detección de antígeno urinario y las amplificaciones de ácido nucleico en muestras respiratorias (64). La PCRtr ofrece ventajas como alta sensibilidad, obtención rápida de resultados y el potencial de detectar infecciones causadas por varios serogrupos de Legionella pneumophila y no -pneumophila $(65,66)$.

Chlamydophila pneumoniae y Mycoplasma pneumoniae son agentes etiológicos de neumonía. $C$. pneumoniae causa del $9-15 \%$ de los casos de neumonía y el $M$. pneumoniae del 7-22\% $(67,68)$. La incidencia más alta de Chlamydophila pneumoniae y Mycoplasma pneumoniae es en niños de edad escolar, entre 5 a 14 años de edad.

Los agentes causales de infecciones respiratorias son difíciles de distinguir. La PCRtr dúplex o multiplex ha sido una gran herramienta para el diagnostico acertado en estas enfermedades, diferenciando en un mismo tubo agentes etiológicos diferentes como en el caso de Chlamydophila pneumoniae, Mycoplasma pneumoniae y Legionella pneumophila $(69,70)$

Otra aplicación en investigación básica con células bacterianas, ha sido la cuantificación de ARN y la valuación de su expresión. Este es el caso del estudio de transcriptos del gen mecA en Staphylococcus aureus meticilin resistente, en donde se correlaciona la presencia del gen, con su expresión y el efecto de sus genes represores e inductores sobre esta (62). A manera de cierre, la PCRtr continuará evolucionando, al ser una herramienta versátil, que permite su uso en gran cantidad de áreas de investigación básica y aplicada. $N$ 


\section{Referencias}

1. Mullis BK. The unusual origin of the Polymerase Chain Reaction. Sci Am. 1990;262:56-65.

2. McPherson JD, Marra M, Hillier L, Waterston RH, Chinwalla A, Wallis J, et al. A physical map of the human genome. Nature. 200;409:934-941.

3. Rodriguez IP, Barrera H. La reacción en cadena de la polimerasa a dos décadas de su invención. Ciencia UANL.2004;7:323-332.

4. Mocellin S, Rossi CR, Pilati P, Nitti D,Marincola FM. Quantitative real-time PCR: a powerful ally in cancer research. Trends Mol Med. 2003;9:189-195.

5. Templeton KE, Scheltinga SA, Graffelman WA, Van Schie JM, Crielaard JW, Sillekens P, et al. Comparison and evaluation of realtime PCR, real-time nucleic acid sequence-based amplification, conventional PCR, and serology for diagnosis of Mycoplasma pneumoniae. J Clin Microbiol. 2003;41:4366-4371.

6. Costa J. Reacción en cadena de la polimerasa (PCR) a tiempo real. Enferm Infecc Microbiol Clin. 2004;22:299-305.

7. Luque JC, Herráez SA. Texto ilustrado de Biología Molecular e Ingeniería Genética. Ed. Harcourt.2000. pg 313.

8. Innia M, Gelfand D, Sninsky J. PCR strategies. Academic Press New York USA.1995:325.

9. Choi S, Kim S-H, Kim H-J, Lee D-G, Choi J-H, Yoo J-H, et al. Multiplex PCR for the detection of genes encoding aminoglycoside modifying enzymes and methicillin resistance among Staphylococcus species. J. Korean Med Sci. 2003;18:631-636.

10. Jiménez A, Gomez R, Agirre X, Barrios M, Navarro G, Eneriz E, et al. PCR en tiempo real, una nueva herramienta para la toma de decisiones clínicas. Haematologica. 2006;91:27-34.

11. Kaltenboeck B, Wang C. Advances in real-time PCR: application to clinical laboratory diagnostics. Adv Clin Chem. 2005;40:219-259.

12. Heid CA, Stevens J, Livak JK, Williams M. Real Time Quantitative. Genome Res.1996;6:986-994.

13. Equipos para RT-PCR. Disponible en www.Biorad.com.

14. Rutledge RG, Cote C. Mathematics of quantitative kinetic PCR and the application of standard curves. Nucleic Acids Res. 2003;31:3-6.

15. Bustin SA, Mueller R. Real-time reverse transcription PCR (qRT-PCR) and its potential use in clinical diagnosis. Clin Sci.2005;109:365-379.

16. Kubista M, Andrade JM, Bengtsson M, Forootan A, Jonak J, Lind $\mathrm{K}$, et al. The real-time polymerase chain reaction. Mol Aspects Med. 2006;27:95-125.

17. Wong M, Medrano JF. Real-time PCR for mRNA quantitation. Biotechniques. 2005;39:75-85.

18. Peirson S, Butler J, Foster R. Experimental validation of novel and conventional approaches to quantitative real-time PCR data analysis. Nucleic Acids Res. 2003;31:e73.

19. Pfaffl M. A new mathematical model for relative quantification in Real-Time RT-PCR. Nucleic Acids Res. 2001;29:e45.

20. Kainz P. The PCR plateau phase - towards an understanding of its limitations. Biochim Biophys Acta. 2000;1494:23-27.

21. Al-Soud WA, Jhonsson LJ, Radstrom P. Identification and Characterization of Immunoglobulin $\mathrm{G}$ in Blood as a Major Inhibitor of Diagnostic PCR. J Clin Microbiol. 2000;38:345-350.
22. Al-Soud WA, Rådström P. Purification and characterization of PCR-inhibitory components in blood cells. J Clin Microbiol. 2001;39:485-493.

23. Gudnason H, Dufva M, Bang DD, Wolff A. Comparison of multiple DNA dyes for real-time PCR: effects of dye concentration and sequence composition on DNA amplification and melting temperature. Nucleic Acids Res. 2007;35:1-8.

24. Nazarenko I, Lowe B, Darfler M, Ikonomi P, Schuster D, Rashtchian A. Multiplex quantitative PCR using self-quenched primers labeled with a single fluorophore. Nucleic Acids Res. 2002;30:e37.

25. Bustin SA. Quantification of mRNA using real-time reverse transcription PCR (RT-PCR): trends and problems. J Mol Endocrinol. 2002;29:23-39.

26. Provenzano M, Rossi C, Mocellin S. The usefulness of quantitative real-time PCR in immunogenetics. Third Quarter. 2001:89-91.

27. Burggraf S, Olgemoller B. Simple technique for internal control of real-time amplification assays. Clin Chem. 2004;50:819-825.

28. Memorias Curso teórico-practico de PCR en tiempo real. Corpogen. Julio 26 y 27 de 2007.

29. Espy MJ, Uhl JR, Sloan LM, Buckwalter SP, Jones MF, Vetter EA, et al. Real-time PCR in clinical microbiology:applications for routine laboratory testing. Clin Microbiol Rev. 2006;19:165-256.

30. Yuan J, Reed A, Chen F, Stewart N. Statistical analysis of real-time PCR data. BMC Bioinformatics. 2006;85:1471-2105.

31. Pfaffl M, Hageleit M. Validities of mRNA quantification using recombinant RNA and recombinant DNA external calibration curves in real-time RT-PCR. Biotechnol Lett. 2001;23:275-282.

32. Gibson U, Heid CA, Williams PM. A Novel method for real time quantitative RT-PCR. Genome Res.1996;6:995-1001.

33. Livak K, Schmittgen T. Analysis of relative gene expression data using real-time quantitative PCR and the 2(-Delta Delta C(T)) Method. Methods. 2001;25:1402-1408.

34. Zucol F, Ammann RA, Berger C, Aebi C, Altwegg M, Niggli FK, et al. Real-time quantitative broad-range PCR assay for detection of the 16S rRNA gene followed by sequencing for species identification. J Clin Microbiol. 2006;44:2750-2759.

35. Vandecasteele SJ, Peetermans WE, Merckx R, Eldere V. Quantification of expression of Staphylococcus epidermidis housekeeping genes with Taqman quantitative PCR during in vitro growth and under different conditions. J Bacteriol. 2001;183:7094-7101.

36. Rodicio M, Mendoza M. Identificación bacteriana mediante secuenciación del ARNr 16S:fundamento,metodología y aplicaciones en microbiología clínica. Enferm Infecc Microbiol Clin. 2004;22:238-245.

37. Beck B, Hoelsmeyer M, Paul S, Downs D. A mutation in the essential gene gmk (encoding guanlyate kinase) generates a requirement for adenine at low temperature in Salmonella enterica. J Bacteriol. 2003;185:6732-6735.

38. Skurray R, Brow M. Identification of Suitable internal controls to study expression of a Staphylococcus aureus multidrug resistance systems by quantitative real-time PCR. J Microbiol Meth.2007;70:355-362.

39. Unkles S, Logsdon J, Robinson K, Kinghorn J, Duncan J. The tpiA gene is a transcripcional isomerase and glyceraldehyde-3-phosphate dehydrogenase in oomycota. J Bacteriol.1997;179:6816-6823. 
40. Xu Y, Hong Y, Hall T. Rice triosephosphate isomerase gene 5 ' sequence directs $\otimes$-glucuronidase activity in trangenic tobacco but requires an intron for expression in rice. Plant Physiol.1994;106:459-467.

41 Plamannt D. Michael, Stauffer VG. Regulation of the Escherichia coli glyA Gene by the metR Gene Product and Homocysteine. J Bacteriol. 1989;171:4958-4962.

42. Purvis IJ, Loughlin L, Bettany AJ, Brown AJ. Translation and stability of an Escherichia coli beta-galactosidase mRNA expressed under the control of pyruvate kinase sequences in Saccharomyces cerevisiae. Nucleic Acids Res. 1987;15:7963-7974.

43. Poysti J, Nathan, Oresnik J. Characterization of Sinorhizobium meliloti triose phosphate isomerase genes. J Bacteriol. 2007;189:3445-3451.

44. Schmittgen TD, Zakrajsek BA. Effect of experimental treatment on housekeeping gene expression: validation by real-time, quantitative RT-PCR. J Biochem Biophys Methods. 2000;46:69-81.

45. Rubie C, Kempf K, Hans J, Su T, Tilton B, Georg T, et al. Housekeeping gene variability in normal and cancerous colorectal, pancreatic, esophageal, gastric and hepatic tissues. Mol Cell Probes.2005;19:101-109.

46. Dheda K, Huggett J, Bustin S, Johnson M, Rook G, Zumla A. Validation of housekeeping genes for normalizing RNA expression in real-time PCR. Biotechniques 2004;37:112-119.

47. Huggett J, Dheda K, Bustin S, Zumla A. Real-time RT-PCR normalisation; strategies and considerations. Genes Immun. 2005;6:279-284.

48. Bonilla E, Párraga M, López LA, Escolar F, Del Marzo J. Cuantificación de la expresión génica a partir de un número limitado de células mediante RT-PCR en tiempo real. Bioquimia. 2002;27:3-7.

49. Burkhard M, Charlotta L, Wagner M, Kra“mer N, Hoorfar J. Enumeration of Salmonella bacteria in food and feed samples by real-time pcr for quantitative microbial risk assessment. Appl Environ Microbiol. 2008;74:1299-1304.

50. De Medici D, Croci L, Delibato E, Di Pasquale S, Filetici E, Toti L. Evaluation of DNA extraction methods for use in combination with SYBR Green I Real-Time PCR to detect Salmonella enterica serotype Enteritidis in Poultry. Appl Environ Microbiol. 2003;69:3456-3461.

51. Burkhard M, Paccassoni E, Fach P, Bunge C, Martin A, Helmuth R. Diagnostic Real-Time PCR for detection of Salmonella in food. Appl Environ Microbiol. 2004;70:7046-7052.

52. Artin I, Björkman P, Cronqvist J, Rådström P, Holst E. First case of type $\mathrm{E}$ wound botulism diagnosed using real-time PCR. J Clin Microbiol. 2007;45:3589-3594.

53. Fenicia L, Anniballi F, De Medici D, Delibato E, Aureli P. SYBR green real-time PCR method to detect Clostridium botulinum type A. Appl Environ Microbiol. 2007;73:2891-2896.

54. Yoon SY, Chung GT, Kang DH, Ryu C, Yoo CK, Seong WK. Application of real-time pcr for quantitative detection of Clostridium botulinum Type A toxin gene in food. Microbiol Immunol. 2005;49:505-511.

55. Edwards KJ, Kaufmann ME, Unders NA. Rapid and accurate identification of coagulase-negative staphylococci by real-time PCR.. J Clin Microbiol. 2001;39:3047-3051.
56. Kane TD, Alexander JW, Johannigman JA. The detection of microbial DNA in the blood: a sensitive method for diagnosing bacteremia and/or bacterial translocation in surgical patients. Ann. Surg. 1998;227:1-9.

57. Cursons RT, Jeyerajah E, Sleigh JW. The use of polymerase chain reaction to detect septicemia in critically ill patients. Crit Care Med.1999;27:937-940.

58. Lu JJ, Perng CL, Lee SY, Wan CC. Use of PCR with universal primers and restriction endonuclease digestions for detection and identification of common bacterial pathogens in cerebrospinal fluid. J Clin Microbiol. 2000;38:2076-2080.

59. Rantakokko-Jalava K, Nikkari S, Jalava J, Eerola E, Skurnik M, Meurman O, et al. Direct amplification of rRNA genes in diagnosis of bacterial infections. J Clin Microbiol. 2000;38:32-39.

60. Mariani BD, Martin DS, Levine MJ, Booth RE Jr, Tuan RS. The coventry award polymerase chain reaction detection of bacterial infection in total knee arthroplasty. Clin Orthop Relat Res. 1996;331:11- 22.

61. Klaschik S, Lehmann LE, Raadts A, Book M, Hoeft A, Stuber F. Real-time PCR for detection and differentiation of gram-positive and gram-negative bacteria. J Clin Microbiol. 2002;40:4304-4307.

62. Rosato EA, Craig A, William, Archer LG. Quantitation of mecA transcription in oxacillin-resistant Staphylococcus aureus clinical isolates. J Bacteriol. 2003;185:3446-3452.

63. Volkmann H, Schwartz T, Bischoff P, Kirchen S, Obst U. Detection of clinically relevant antibiotic-resistance genes in municipal wastewater using real-time PCR (TaqMan). J Microbiol Methods. 2004;56:277-286.

64. Theis T, Skurray AR, Brown HM. Identification of suitable internal controls to study expression of a Staphylococcus aureus multidrug resistance system by quantitative real-time PCR. J Microbiol Methods. 2007;70:355-362.

65. Diederen B, Kluytmans J, Vandenbroucke CM, Peeters MF. Utility of Real-Time PCR for Diagnosis of Legionnaires' Disease in Routine Clinical Practice. J Clin Microbiol. 2008;46:671-677.

66. Stolhaug A, Bergh K. Identification and differentiation of Legionella pneumophila and Legionella spp. with real-time PCR targeting the 16S rRNA gene and species identification by mip sequencing. Appl. Environ. Microbiol. 2006;72:6394-6398.

67. Templeton KE, Scheltinga SA, Graffelman AW, Van Schie JM, Crielaard JW, Sillekens P, et al. Comparison and evaluation of real-time PCR, real time nucleic acid sequence-based amplification, conventional PCR, and serology for diagnosis of Mycoplasma pneumoniae. J. Clin. Microbiol. 2003;41:4366-4371.

68. Michelow IC, Olsen K, Lozano J, Rollins NK, Duffy LB, Ziegler $\mathrm{T}$, et al. Epidemiology and clinical characteristics of communityacquired pneumonia in hospitalized children. Pediatrics. 2004;113:701-707.

69. Gullsby K, Storm M, Bondeson K. Simultaneous Detection of Chlamydophila pneumoniae and Mycoplasma pneumoniae by Use of Molecular Beacons in a Duplex Real-Time PCR. J Clin Microbiol. 2008;46:727-731.

70. Welti, Jaton MK, Altwegg M, Sahli R, Wenger A, Bille J. Development of a multiplex real-time quantitative PCR assay to detect Chlamydia pneumoniae, Legionella pneumophila and Mycoplasma pneumoniae in respiratory tract secretions. Diagn Microbiol Infect. Dis. 2003;45:85-95. 